\title{
Direct Support to Private Firms: Evidence on Effectiveness
}

\author{
Geeta Batra and Syed Mahmood*
}

\begin{abstract}
World Bank Policy Research Working Paper 3170, November 2003
The Policy Research Working Paper Series disseminates the findings of work in progress to encourage the exchange of ideas about development issues. An objective of the series is to get the findings out quickly, even if the presentations are less than fully polished. The papers carry the names of the authors and should be cited accordingly. The findings, interpretations, and conclusions expressed in this paper are entirely those of the authors. They do not necessarily represent the view of the World Bank, its Executive Directors, or the countries they represent. Policy Research Working Papers are available online at http://econ.worldbank.org.
\end{abstract}

\footnotetext{
* The authors wish to thank Michael Klein, Neil Roger, William Stevenson, Linda Mora, James Emery and Tom Davenport for many helpful comments.
} 


\section{TABLE OF CONTENTS}

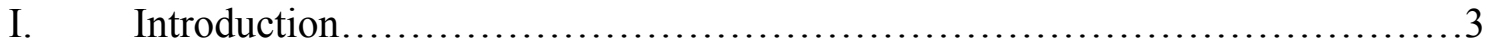

II. Provision of Finance..................................................... 3

A. Credit Lines (non-agricultural) .................................... 3

B. Micro-finance..................................................... 6

C. Rural Finance..................................................... 9

III. Technical Assistance, Extension, Training and Technology Upgrading......... 10

A. Technical Assistance to Private Firms................................ 10

B. Interventions to Increase Private Sector Training........................ 16

C. Support to Technology Development................................ 17

IV. Conclusions......................................................... 19

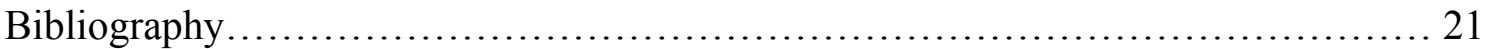

$\underline{\text { Annex }}$

1. World Bank projects with credit line components 


\section{Introduction}

1. Governments use a variety of instruments to provide direct support to private enterprises. These include the provision of finance (subsidized and/or directed credit) and business development services (management and marketing advice to small businesses, agricultural extension services, support for enterprise level training and support to technology development). These interventions are distinct from those that support enterprises indirectly by establishing a policy and legal environment conducive to enterprise development.

2. How effective have these direct support schemes been? This paper attempts to provide some answers to this question by surveying the available literature on the effectiveness of direct support interventions. The surveyed literature covers both academic papers and project/program evaluations. Several, but not all, of the projects and programs evaluated are that of the World Bank Group.

3. Evaluations of direct support programs vary in their methodologies. Detailed costbenefit analyses are rare. Where available, impact evaluations suggest that the performance has been mixed at best. The evidence indicates that active intervention does not work unless the basic environment for private sector development is sound. Public policy thus needs to focus on creating an enabling environment, key elements of which include a sound legal and judicial system which supports low-cost contract enforcement, good infrastructure, a policy playing field which is level in terms of ease of registration, taxes and investment incentives for all enterprises - large and small, domestic and foreign.

4. The rest of the paper reviews the evidence for direct support of the following types: a) credit lines (non-agricultural), b) micro-finance, c) rural finance, d) technical assistance to private firms, e) interventions to increase private sector training and f) support to technology development.

\section{Provision of Finance}

\section{A. Credit lines (non-agricultural)}

5. Many governments have programs to deliver subsidized long-term credit to private firms through financial intermediaries. Often supported by donors, these programs aim at promoting industrial growth and are based on the premise that lack of long-term credit is a major constraint to industrial investment and capacity utilization. Evidence suggests that such programs often do not achieve their aims. A recent study of firms in thirty countries (nineteen developed and eleven developing) shows that while term finance is positively associated with firm growth, government intervention in providing such finance has not been successful when there were weaknesses in the underlying 
institutional infrastructure. ${ }^{1}$ The results indicate that while the stock market and development of legal institutions are important in facilitating firm growth, there is no evidence that government subsidies to firms lead to more firms growing at higher than predicted rates.

\section{World Bank projects}

6. Evidence on the performance of World Bank-supported credit line operations also casts doubt on the efficacy of subsidized credit. Credit lines have been a major tool of World Bank support to the private sector. These operations involve loans to one or more financial intermediaries which then on-lend to private enterprises. The overall objective is typically to promote supply response from enterprises by helping to expand capacity, improve productivity and diversify lines of business through investment and enterprise restructuring. Export industries are emphasized in several loans. Many loans are earmarked for, or give priority to, SMEs. In many cases, the loans are made in the context of recently concluded, or on-going, policy reforms. The aim, in these cases, is to enable private firms to respond to the reforms.

7. Some credit lines are stand-alone operations. However, most are part of broader projects which have other components, such as technical assistance to enterprises, financial intermediaries and other public sector institutions that provide services to the private sector. Some projects also have components dealing with sectoral reforms, most notably financial sector reforms. Often, the credit lines are seen as complementary to the other components. For example, several projects are based on the premise that institutional development of financial intermediaries would require them to "learn-bydoing"; hence credit lines are included as complements to TA components.

The World Bank has not done any major review of on-lending operations in recent years. However, it has evaluated several projects with on-lending components. This section summarizes the findings from a sample of 30 such projects, most of which had closed in the last five years and for which OED evaluations or implementation completion reports have been completed (see Annex1 for the list of projects).

8. Much of the performance-related information in the OED evaluations is on input indicators, i.e., disbursement of loans from credit lines, rather than on outcome or impact indicators that reflect the objectives of the projects. Sixteen out of the thirty projects appear to have performed well by the disbursement criterion. The rest have had a poor disbursement record. Insufficient demand for loans was a major reason for poor disbursement. This, in turn, was caused by several factors including macro-economic instability and economic uncertainty, availability of other cheaper lines of credit, and relatively high cost of borrowing from the credit line (caused sometimes by cumbersome World Bank procedures). Lack of qualified financial intermediaries was also identified as a problem in some projects.

9. Evidence on outcomes is relatively scarce. Out of eighteen projects for which some outcome data are available, twelve show some positive results, such as increased output,

${ }^{1}$ Demirguc-Kunt and Maksimovic (1996). 
sales or exports, achievement of target rates of return, and increased job creation. However, even for these projects, it is not clear whether the results justify the resources spent on the projects. Most evaluations are not based on an in-depth analysis required to answer such questions. There are some projects where the credit lines have disbursed well but the expected outcomes have not been achieved. ${ }^{2}$ In some projects, the outcomes were achieved but the projects appeared to have had little to do with the results. ${ }^{3}$ On sustainability and cost-effectiveness, much of the data are only on repayment rates. Here, the record is mixed. Six projects, out of ten for which data are reported, show good repayment rates while the rest show high rates of default by sub-borrowers.

10. To summarize, it is clear that where the investment climate is poor, credit line projects do not do well. Where they do appear to do well, it is not clear if they are costeffective and provide additionality.

\section{IFC's project financing facility}

11. IFC's Africa Enterprise Fund (AEF) invested in SMEs through loans, equity, guarantees and quasi-equity. From its inception in 1988 to 1999 , AEF had disbursed $\$ 100$ million for 157 projects, funding on average 40 per cent of project costs. Evidence on performance of the fund is available from a 1999 evaluation by IFC's OEG. The evaluation covered 57 AEF projects approved during FY93-98, i.e., fiftyper cent of all AEF projects approved during this period. ${ }^{4}$

12. Approximately half of the projects $(56 \%)$ had a satisfactory development outcome. ${ }^{5}$ This is a lower score than that achieved for all IFC projects approved during CY91-93, which were subsequently evaluated (67\% with satisfactory ratings), and for comparable IFC mainstream projects in Africa (78\% satisfactory). ${ }^{6}$ According to the evaluation report, the most significant impacts of AEF projects have been in the form of job creation and the creation, or enhancement, of linkages with other local enterprises.

13. On average, AEF-supported projects did not do well in terms of financial profitability for IFC. In FY99, less than half of the investments were rated as having a satisfactory

\footnotetext{
${ }^{2}$ For example, in one project in Africa, disbursements were high but the expected expansion in exports did not materialize due to a deterioration in the overall investment climate caused by high inflation and currency depreciation.

${ }^{3}$ For example, in one project the assisted enterprises achieved significant increases in non-traditional exports, as was the goal of the Bank project. However, the OED evaluation suggests that the project had only limited contribution to this.

${ }^{4}$ IFC, An Evaluation of IFC's Investments through the Africa Enterprise Fund, (2000),

${ }^{5}$ The development outcome rating used in the evaluation is a synthesis of underlying ratings on five performance indicators: a) project business success, ii) company business success, iii) growth of productive private enterprise and efficient capital markets, iv) growth of the economy and v) living standards. Each of these indicators reflect several dimensions. For example, the rating on living standards was based on the project's contribution to social objectives, such as employment generation, living standards of employees, non-wage benefits and training provided. Ratings on the "growth of productive private enterprise" indicator took into account factors such as upstream and downstream linkages to private firms, demonstration effects, regulatory improvements, new technology and enhanced private ownership. It is unclear how rigorously the judgments were made. The evaluation report acknowledges that there was an element of subjectivity in the ratings.

${ }^{6}$ The mainstream Africa projects to which this figure relates excludes projects in the following sectors: financial markets, extractive industries, chemicals and petrochemicals, and infrastructure - sectors in which the AEF was not very active.
} 
investment outcome. ${ }^{7}$ Expansion projects, projects with non-indigenous or foreign sponsors, non-exporting projects which had foreign currency revenues and larger projects (cost over $\$ 2.5$ million) had a higher proportion of satisfactory ratings. Investment outcomes were closely correlated with development outcomes, with $72 \%$ of the projects having the same ratings for both dimensions.

14. The performance of the overall AEF portfolio has also not been satisfactory, although it has improved over earlier program years FY95-98. ${ }^{8}$ The failure rate, reflected in the low interest collection rate, the negative equity returns, and the high rate of write-offs and reserves, was high relative to the rest of IFC's portfolio.

15. In summary, the AEF has had poor financial results that limited the development impact of the projects financed. Only half the projects evaluated had significant development impact. The AEF has clearly helped to fill a large gap by financing projects which otherwise might not have proceeded, due to the lack of term finance in Africa and the reluctance of local financial intermediaries to assume the high risk of investing in SMEs. However, these results have been achieved at a considerable cost. The program has required a cross-subsidy of about $\$ 5$ million a year to cover loses after operating expenses. This is high relative to the approval volume of \$28 million and an average outstanding portfolio of \$55 million during FY97-99. The evaluation concluded that while, to a large extent, these results are expected given the higher risk of SME investments and difficult economic environment in most African countries, direct IFC lending to SMEs will "ultimately not be profitable due to high delivery costs, and can help only a very limited number of enterprises (about 40-50 per year in the entire subSaharan Africa region)." 9 IFC has subsequently modified its strategy of financial support to SMEs by moving towards wholesale financing through intermediaries and phasing out direct financing of SMEs.

\section{B. Micro-finance}

16. More than 10 million households in the developing world are currently benefiting from access to micro-credit. Micro-finance institutions have used a variety of approaches to reach these households. In addition, they have also used dynamic incentives, regular repayment schedules, and collateral substitutes to help maintain high repayment rates. However, while these programs have been remarkably successful in their outreach and loan recovery, they have had a mixed record on sustainability.

17. A recent survey of the performance of 72 micro-finance programs with a commitment to financial sustainability found most to be operationally, but not financially,

\footnotetext{
${ }^{7}$ Satisfactory loans were those which were current in their payments and had no reserves. Any investment that had specific reserves or was in arrears was rated less than satisfactory. Equity investments were rated based on their estimated IRR relative to the notional interest rate on a loan. The main causes for poor performance were: a) inability to compete; b) adverse market conditions, including wrong location, declining or unexpectedly low prices, inability to devote much time and effort to marketing; c) sponsor's weakness: many entrepreneurs did not have sufficient resources to put into the enterprise in the event of a cost overrun or weak financial performance; and d) poor policy environment and inadequate infrastructure.

${ }^{8}$ Detailed data on financial results are available in IFC (2000).

${ }^{9}$ IFC (2000), page 3-4
} 
sustainable. ${ }^{10}$ With a few exceptions, the micro-finance programs studied were heavily subsidized. ${ }^{11}$ A study of four major micro-finance programs in Asia found that, while programs were very successful in terms of their outreach, they were heavily dependent on subsidies with a low cost recovery. ${ }^{12}$ Overall, micro-finance experts believe that at best only $5 \%$ of existing micro-finance programs in the world can be expected to be ever financially sustainable. The rest will either have to cease operations or continue to depend on subsidies. ${ }^{13}$ The main reasons for failure to attain financial sustainability include high costs and failure to adequately pass on costs to clients. Average returns to equity for the 72 programs was $9.3 \%$. Most other micro-credit programs have lower, or even negative returns on equity.

18. There are few reliable estimates of the net economic impact of these programs. An exception is Hulme and Mosely (1996) which shows that programs that have achieved higher levels of financial sustainability make larger net impacts on changes in borrowers' incomes. However, within programs, wealthier households benefit more than the poor. ${ }^{14}$ An evaluation of a large micro-credit program in Bangladesh, the Bangladesh Rural Advancement Committee (BRAC), finds that micro-credit has had a significant impact in reducing vulnerability by helping to build assets and making women more aware of social issues. The impact on income depended on the level of borrowing and the initial income level of the household, and was greatest on moderately-poor households who borrowed more than $\$ 200 .{ }^{15}$

19. There have been very few studies on the costs and benefits of subsidized provision of micro-finance. One study which attempts such an analysis for the Grameen Bank estimates a cost-benefit ratio of 0.91 for women borrowers and 1.48 for men. ${ }^{16}$ Benefits are measured in terms of household consumption which evidently increases less when men borrow from the Grameen Bank. The study shows that cost-benefit ratios for Grameen Bank's credit programs are better than many alternative poverty alleviation programs in Bangladesh, such as food-for-work programs.

20. Successful micro-credit programs share many characteristics. High repayment rates can be attributed to community responsibility schemes and the reputational interest of

\footnotetext{
${ }^{10}$ Morduch (1999). Operational sustainability refers to the ability of institutions to generate enough revenue to cover operating costs but not necessarily the full costs of capital. Financial sustainability refers to whether the institution requires subsidies inputs in order to be able to continue operations, i.e., whether it is able to cover its financial costs. ${ }^{11}$ The exceptional cases include BancoSol (Bolivia) and BRI (Indonesia). BRI's microcredit system broke even in just two years and has been profitable since 1986 and independent of subsidy since 1987. The 1996 return on assets was $5.7 \%$ before tax. BancoSol, which had 81,555 active clients and a loan portfolio of $\$ 74$ million at the end of 1998, became financially sustainable in less than two years after it opened. In 1998, it reported net profits of $\$ 3.5$ million, a return on assets of $4.2 \%$ and return on equity of $28.9 \%$. It was the most profitable bank in Bolivia in 1997 and 1998. Robinson (2001).

${ }^{12}$ Yaron (1997) The four programs studied are in Indonesia (BKK and BUD), Thailand (BAAC) and in Bangladesh (Grameen Bank). Outreach is measured by the value and number of loans extended, types of financial services, real annual growth of the assets of the micro-financial institutions and degree of womens' participation.

${ }^{13}$ Morduch, op. cit. Morduch argues that the key to efficiency is hard budget constraints, not necessarily profits. According to him, "Some donors already use strict and explicit performance targets when lending to micro-finance institutions, conditioning future tranches on performance to-date" (Morduch 1999, pg. 1593).

${ }^{14}$ Hulme and Mosely (1996).

${ }^{15}$ Zaman (1999).

${ }^{16}$ Khandker (1998).
} 
borrowers to retain access to financial services. Stable economic conditions, including low inflation, also help by reducing uncertainty and raising returns on investment. Liberal interest regimes have proven to be important for the viability of micro-finance schemes. One of the critical factors contributing to the financial sustainability of Indonesia's BRI program is that banks gave loans at market rates while keeping costs low. In many countries, reform of usury laws may be necessary to allow micro-finance institutions to charge rates that cover the costs of capital. In sum, the broad lessons about the design of financial products for private parties, and the basic rules of markets, also apply to microfinance institutions. Other factors which contribute to the success of micro-finance institutions include a high degree of management autonomy in the formulation of operational policies; low-cost delivery, innovative and flexible loan terms and conditions, close monitoring of loan performance and servicing of areas with high population density.

\section{World Bank micro-finance projects}

21. A 1999 OED evaluation of the Bank's micro-finance operations assessed the performance of 15 completed projects, including 3 stand-alone micro-finance projects and 12 projects with micro-finance components. ${ }^{17}$ Only five of the fifteen projects were rated as successful. Evaluation results suggest that micro-finance projects were performing less effectively than Bank projects in general and that many of these were unlikely to be sustainable. However, the evaluation did note indications of performance improvements in relatively newer projects.

22. The evaluation found that the design of Bank projects had lagged behind advances in thinking on good practices in the micro-finance industry, in particular the need for a financial systems perspective, which emphasizes the sustainability of micro-finance institutions and gives priority to institution building over subsidizing borrowers. Only five of the 15 operations evaluated by OED had followed the financial systems approach. Four of them had a satisfactory rating while nine of the ten projects that did not follow this approach had an unsatisfactory rating.

23. The evaluation report concluded that the Bank's comparative advantage lies in supporting policy change rather than direct lending. The Bank should thus help clients: a) improve the policy environment toward creating a more liberal financial sector by seeking to eliminate interest rate controls on loans and by introducing the necessary legal framework; b) encourage non-bank micro-finance institutions to access commercial funding and build liquidity management capabilities; and c) develop appropriate ways to regulate and supervise micro-finance institutions that mobilize funds from the public.

24. The evaluation report also argued for greater emphasis on the commercial viability of micro-finance institutions. Earlier micro-finance projects of the Bank had paid little

\footnotetext{
${ }^{17}$ OED (1999).
} 
attention to the financial details of participating institutions, such as loan recovery rates or costs of granting and administering loans. Recent Bank projects provide more information, but it is still not possible to tell if the institutions supported are designed to be commercially viable. Bank experience indicates that lack of attention to financial details weakens performance.

25. Many of the early micro-finance projects were designed on the premise that sustainability was not possible and that subsidies would always be required. These subsidies have traditionally been in the form of below-market interest rates for borrowers which distort resource allocation. Also, experience indicates that higher-income borrowers are better placed to capture these subsidies. The report cautions against interest-rate subsidies which distort resource allocation and are often captured by higherincome borrowers. It argues that it is better to deliver subsidies as incentives to participating institutions to develop the necessary infrastructure to reach the targeted population. At the same time, subsidies are better targeted for micro enterprise finance institutions (MFIs) with the greatest potential for sustainability, to provide appropriate incentives and discipline.

26. Evaluation of four World Bank micro-finance projects that closed more recently show relatively better results. Three projects had satisfactory outcomes reflected in significant increases in household income and operational sustainability of most of the participating micro-finance institutions. Some of these institutions were also financially sustainable.

27. To conclude, micro-finance institutions have shown that despite high transaction costs and no collateral, it is possible to lend profitably to low-income households. However, many of these programs remain dependent on subsidies. Typically, it is unclear what the subsidy dependence of any particular micro-finance scheme is and what donors are "buying" for it. Also, as in the case of other public interventions to support firms, sound cost-benefit analyses are missing or rare. Micro-finance schemes hold promise, but better disciplines are needed to target scarce subsidies, where subsidies are required to sustain micro-finance schemes.

\section{Rural finance}

28. The last major OED review of the World Bank's work on agricultural credit and rural finance was completed in 1993. ${ }^{18}$ The 1993 review looked in-depth at 41 projects that had been completed in the five years preceding the review. It also examined the ratings of 204 credit projects completed during 1975-92. These projects provided medium to long-term credit to farmers or agro-industrial and marketing firms. Some also offered seasonal or other short-term finance. Most of the projects were approved in the early 1980s and completed before 1990.

\footnotetext{
${ }^{18}$ OED (1993). There was a follow-up to this in 1996 which looked at a more limited set of issues; OED
} (1996). 
29 . Of the 204 projects, $23 \%$ were rated as unsatisfactory. These ratings are for the projects as a whole; performance was worse on the credit components with $47 \%$ being unsatisfactory. Several projects had positive results. They (a) helped increase crop, livestock, and industrial production, b) fostered substantial improvements in assets and c) enhanced the capacities of the implementing agencies. However, there were several deficiencies reported. Project design typically paid little attention to the mobilization of rural savings. Most credit institutions were far from being financially viable caused by factors including high delinquency rates, rapid de-capitalization due to high inflation and negative interest rates. Not enough attention was paid to managing delinquency and developing appropriate criteria for assessing eligibility for loans or debt rescheduling.

30. A recent review of the World Bank's rural finance projects approved during FY94-99 reported a mixed performance. ${ }^{19}$ During FY94-99, the Bank approved 101 projects with rural finance components (either stand-alone or with rural finance components). The rural finance loan amount associated with these projects is $\$ 4.12$ billion, i.e. an average of about 0.7 billion per year, with an increasing trend over time. Positive findings on the portfolio performance include better performance and better incentive systems related to loan collection and increased attention to setting appropriate interest rates. On the negative side, there is inadequate attention to institutional subsidy dependence and insufficient analysis of financial and non-financial institutional aspects.

\section{Technical Assistance, Extension, Training and Technology Upgrading}

\section{A. Technical assistance to private firms}

31. Technical assistance programs for SMEs gained prominence in the 1970s. These programs typically provide support, usually through public sector agencies, to help SMEs build technical, marketing and managerial skills. Often the projects also support capacitybuilding of local institutions, usually in the public sector, that provide technical assistance (TA) to SMEs, and financial institutions that provide credit to SMEs.

32. On balance, the impact of these programs has been limited. A study of World Bank lending for SMEs found that the Government-executed schemes were mostly "slow to get off the ground, costly and ineffective". ${ }^{20}$ Many project development facilities reach only a small number of firms at substantial costs. These often benefit firms that are large by developing country standards. The cost effectiveness of these interventions remains unclear and has not been rigorously evaluated. However, useful findings have emerged from some IFC-sponsored evaluations.

\footnotetext{
${ }^{19}$ Yaron and Charitonenko (2000).

${ }^{20}$ Webster (1991).
} 


\section{IFC's project development facilities}

33. IFC has helped set up a number of project development facilities to, among other things, help entrepreneurs develop project ideas into bankable investment proposals and raise financing for these projects. They are also expected to provide technical assistance, management consulting services, and training. A 1995 review of four such facilities found mixed results. The facilities had helped develop over 240 projects and raise $\$ 300 \mathrm{~m}$ out of the $\$ 500 \mathrm{~m}$ in financing required for the ventures. ${ }^{21}$ Most assisted enterprises were SMEs and appeared to do better than comparable enterprises in the same regions. ${ }^{22}$ In addition to helping entrepreneurs develop ideas into bankable projects and mobilize funding, these facilities influenced local standards for evaluating and structuring projects and helped to create a demonstration effect by fostering successful enterprises that others then emulated.

34. Despite these outcomes, it has not been established that the facilities produced results that justify the resources put into them. Three of the four facilities fell short of their targets with regard to number of project preparation assignments. In all the facilities, less than half of the completed assignments resulted in investments that were actually carried out. Even for the two more mature facilities, (APDF \& CCBAS) only 50 per cent of the assisted ventures appeared viable at the time of the evaluation.

35. The facilities proved to be expensive. Costs per project implemented ranged from $\$ 200,000$ to $\$ 400,000$ (i.e., $8-16 \%$ of realized investments) and exceeded what clients were willing to pay. Fees covered only a small percentage -from $4 \%$ to $27 \%$-of the facilities' total costs. Low fees resulted in inefficiencies. Many clients had little commitment and abandoned the proposals after facilities had spent considerable resources in preparing them. Over time the facilities had increased fees but these were still low compared to the costs. The evaluation concluded that the facilities would have to continue to rely on donor funding or move away from original mandates and start working with larger firms that could afford higher fees

36. More recent evaluations of project development facilities suggest some improvements in the performance of the facilities. The Mekong Project Development Facility (MEDF) is the latest to be evaluated. MPDF was established in 1996 and covers Vietnam, Cambodia and Laos. It helps SMEs prepare bankable business plans, helps them in approaching financiers, and provides them an array of business advisory services. In addition, it works with providers of business support services and financial intermediaries, helping to build their capacity. In terms of activity, MPDF has surpassed original expectations. By the end of 2001, MPDF had completed 96 financial advisory projects and 13 technical assistance projects, and has helped raise $\$ 40.2$ million in financing commitments for 96 projects. About two-thirds of surveyed MPDF clients who

\footnotetext{
${ }^{21}$ These facilities, with their years of establishment, are Caribbean and Central American Business Advisory Services (CCBAS-1981), African Project Development Facility (APDF-1988), South Pacific Project Facility (SPPF-1991), Polish Business Advisory Service (PBAS-1991). IFC has been the lead sponsor and has provided management and a significant share of the financing for these facilities.

${ }^{22}$ There may be an element of self-selection bias here since it is likely that better firms have a greater tendency to seek out and/or receive help from such facilities.
} 
received help with business advisory services reported that MPDF assistance has led to improvements in their performance in terms of planning, quality management, human resource management, and/or environmental management and about 60 percent reported an increase in net profits or annual sales following MPDF-assisted changes. ${ }^{23}$

37. However, the evaluation raises questions about additionality and cost effectiveness. About one-third of the MPDF clients who received financial advice believed that the facility made no difference to the financing they obtained and two-thirds indicated that they would have implemented their project even without bank financing by relying on equity contributions from owners or family members, retained earnings and other sources of equity and debt. ${ }^{24}$ On cost effectiveness, MPDF's performance was better than earlier PDFs (cost per project during the period covered by the evaluation was about $50 \%$ lower than in the earlier PDFs) but still left a lot to be desired. MPDF is collecting roughly $4.8 \%$ of the total cost of services - this is significantly below the $10 \%$ cost recovery originally projected. $^{25}$

38. In brief, the project development facilities require considerable subsidization. It is not clear if the activities supported by the facilities deserve subsidies and, if they do, whether the results achieved justify the amount of subsidies given. Lack of a detailed cost-benefit analysis precludes firmer conclusions. ${ }^{26}$

\section{World Bank SME projects}

39. In addition to providing credit, many World Bank SME projects also provide technical assistance to enterprises. An OED evaluation of five such World Bank SME projects that closed between FY97 and FY01, and an OED impact evaluation study of four SME projects in the Philippines that provided support to private firms during 198892, show mixed results on the technical assistance component. ${ }^{27}$ Three out of the five SME projects did well on the input side, i.e., there was substantial use of the technical assistance (TA) services. However, only one of them reports significantly positive outcomes, with the other two achieving partially successful outcomes. The other two projects, as well as the four SME projects in the Philippines, show little use of the TA services. In the case of Philippines, the credit line component was substantially used and had a good impact, but the performance of the TA component was disappointing.

\footnotetext{
${ }^{23}$ Nexus Associates, Inc. "Evaluation of the Mekong Project Development Facility, Final Report," June 4, 2002, report prepared for IFC, Operations Evaluation Group. The evaluation covered almost all enterprises supported by the MPDF.

${ }^{24}$ However, the companies interviewed for the evaluation suggested that the need to raise money from other sources might have delayed the project, reduced its scope and/or increased the costs of capital.

${ }^{25}$ The front-end fees that the MPDF could charge was limited to US\$100 per project, a condition set by the Government of Vietnam as part of the establishment of MPDF.

${ }^{26}$ It should be noted that, in recent years, there has been a shift in the nature of support provided by the project development facilities with direct support to enterprises no longer being the main instrument of support. Such support is now provided on a more selective basis with the emphasis shifting towards working with intermediaries, such as financial intermediaries and providers of business advisory services.

${ }^{27}$ The five projects were in Burundi, Ghana, Nigeria, Pakistan and Sri Lanka.
} 
40. An earlier World Bank study of the Bank's record in providing TA to SMEs over the period 1973-93 found relatively few cases of satisfactory outcomes. ${ }^{28}$ The study, which is one of the most comprehensive assessments of World Bank assistance to SMEs, reviewed 70 projects, involving $\$ 142$ million in finance for TA. The TA components accounted for $4 \%$ of overall IBRD/IDA financing in these $70 \mathrm{SME}$ projects. In addition to supporting apex units and banks, the projects provided industrial extension, consultancies, and training services for small entrepreneurs, mostly through public sector agencies. The study concludes that most TA services for entrepreneurs failed to meet their objectives, both in the quantity and quality of services delivered. Three main reasons for poor performance were identified: a) poor design of components, ignoring real needs of clients and not well-matched with the capabilities of the implementing institutions; $b$ ) inadequate preparation and supervision on the Bank's part, particularly where components were complex and implementing agencies were weak, and c) poor implementation and weak commitment by public institutions.

41. The successful TA projects tended to be small with modest and clearly defined goals and tried to strengthen existing programs with proven track records rather than launch new initiatives. Institutions with proven competence or exceptional leadership performed far better than weaker institutions that were to be strengthened by projects while simultaneously providing services. Technical assistance that targeted specific sub-sectors were more effective than courses in general business skills.

\section{Other SME programs}

42. The UNCTAD-coordinated EMPRETEC program in Ghana provided training and business advisory services to SMEs. 57 such firms were surveyed in 1997 (reference). On average, beneficiary firms reported positive outcomes in terms of increased employment and sales, which increased by $15 \%$ and $25 \%$ respectively per annum. However, cost recovery of the services was low; on average below $40 \%$. An evaluation of IDB-supported EDCs (employment development centers) in Latin America which supported training and improvement of management practices in SMEs did not find satisfactory results either. There was no systematic evaluation of project impact on clients. At the time of the evaluation, sustainability of the project was in doubt; cost recovery remained low, about $40 \%$ or below in most countries (reference).

43. A recent paper on the experience with business development services in developing countries concludes that public provision of services tends to distort business development service markets and crowd out private providers through subsidized delivery of services. To the extent that it has been measured and evaluated, the impact of government programs on SME performance has been fairly limited. ${ }^{29}$

44. Similar experience is reported for developed countries by an OECD study on public support for SMEs in OECD countries. The study, which covered the late eighties and early nineties, found high administrative costs with less than $10 \%$ of the support designed

${ }^{28}$ Webster (1991).

${ }^{29}$ ILO (2001). 
exclusively to finance the provision or acquisition of advisory and consultancy services. ${ }^{30}$ Although there are a large number of SMEs in OECD countries, few benefited from SME support programs.

45. Commercial providers of such services tend to do better. A study of SME support programs in Korea found that when comparable support services were available from private commercial, government or other non-profit agencies, the services of the commercial agencies were rated higher than public providers. ${ }^{31}$ There were several reasons why the non-profit sources of support were less effective: a) excessive generality of training, information and other support provided; b) difficulties faced by SMEs in accessing such support or taking advantage of it effectively; and c) poor governance by support providers.

46. An example of a successful program is the CIMO program in Mexico. The program provides subsidized training and technical assistance to micro, small and medium enterprises. Its objectives are to raise worker productivity, promote good systems and practices in enterprises, foster industrial clusters and inter-firm linkages, align training supply with training needs. Two evaluations of the program were done in 1995 and 1997 respectively, comparing CIMO-supported firms with a control group of non-supported firms (Tan,2002). The evaluations suggest that the CIMO program made a significant difference. The CIMO-supported firms were more likely to provide training, including formal training courses and training by external trainers, than the control group. These firms had a greater tendency, compared to the control group, to introduce productionenhancing organizational changes (such as team work, quality circles and client orientation) and bring changes in production processes. The CIMO-supported firms had faster rates of increase in capacity utilization and, when economic conditions were adverse, a lower rate of decline in capacity utilization, than the control firms.

47. In recent years, a consensus has emerged in the SME practitioner community that traditional approaches to SME support need to be replaced by more effective interventions. The new approach discourages the use of interest rate subsidies and argues for subjecting business development services to market disciplines. It calls for redirecting efforts away from helping SMEs directly to developing financial and consulting markets that serve SMEs. A reflection of the new approach is the growing emphasis by IFC on increasing the cost-recovery rate in its project development facilities and the Bank's experimentation with a variety of matching grant schemes. Under such schemes, the Bank loans finance part of advisory services, as long as the private firm matches the amount in some proportion. One matching grant scheme, in Mauritius, has so far been evaluated in depth and been found to be ineffective. ${ }^{32}$ Other new approaches aim at reducing the costs of market access or transaction costs for SMEs, by strengthening information systems, and helping develop management tools for SMEs. So far no evaluations exist for such approaches.

\footnotetext{
${ }^{30}$ OECD (1997).

${ }^{31}$ Nugent and Yhee (2001). The paper evaluates the use of support from governmental and other non-profit institutions, sectoral associations and government policies by SMEs in Korea.

32 Biggs (1999) .
} 


\section{Agricultural extension}

48. The main functions of agricultural extension services are to inform farmers of new techniques and to transfer information from farmers to other participants. Public sources, on average, provide about 80 percent of total extension services. Studies show that extension services substantially improve technology adoption rates, awareness and productivity. ${ }^{33}$. However, many public extension services have been inefficient and poorly targeted, and have been unsustainable. World Bank supported agricultural extension projects have generally not produced good results. An OED review of World Bank agricultural research and extension investments that were operational between 1977 and 1992 shows that, of the 33 projects studied, only 10 were rated as satisfactory and the rest as unsatisfactory. ${ }^{34}$ All projects, irrespective of their ratings, had major design and implementation problems. The most common problems were recurrent cost funding problems during and subsequent to the project ( 28 projects), inadequate researchextension linkage ( 26 projects), under-qualified front-line extension staff having insufficient practical knowledge of production systems and relevant technology (17 projects), top-down approaches to developing recommendations (17 projects) and ineffective contact farmer systems (16 projects). Other problems include insufficient availability of technology, little consideration of production economics and risks, and differential access by farmers to resources, insensitivity of projects to specific fiscal, institutional, and farming system conditions, weak commitment of implementing agencies and weak monitoring systems.

49. More recent World Bank projects appear to be only marginally better. OED evaluations of six agricultural extension projects that were completed more recently, rate two as having a satisfactory performance, one being marginally satisfactory and three unsatisfactory. ${ }^{35}$

50. A program involving private sector provision of extension services in Argentina has produced good results. Faced with declining productivity of Argentine dairy farmers, the two largest dairy processors of the country initiated extension services for their suppliers. By 1990, 120 farmers' groups were participating in the program. The results were positive. Although the number of dairy farms supplying one of the processing companies decreased by 24 percent, milk production increased by $15 \%$ between 1976 and 1985 . Milk production at the other processing company jumped by almost 50 percent despite a $6 \%$ decrease in dairy farm areas of suppliers. ${ }^{36}$

51. In some countries, decentralization of public extension institutions has generated benefits in terms of enhancing efficiency, service quality and outreach. There are also

\footnotetext{
${ }^{33}$ Evenson (1977) quoted in World Bank (2002), chapter 2.

${ }^{34}$ Purcell and Anderson (1997).

${ }^{35}$ The satisfactory projects were in Guinea, Mali and Madagascar while the unsatisfactory projects were in Burkina Faso, Chile and Sri Lanka.

${ }^{36}$ Umali-Deininger (1997), quoted in World Bank (2002), chapter 2.
} 
examples of positive results from programs combining private provision with public financing. ${ }^{37}$

\section{B. Interventions to increase private sector training}

52. Training (and re-training) programs generally account for the largest share of expenditures in active labor market programs, usually ranging between $40 \%$ to $60 \%$. Public interventions to increase training by enterprises include revenue-raising training levies to support public provision of pre-employment and in-service training, ${ }^{38}$ tax incentives to train by allowing workers to deduct a multiple of training expenditures from income $; 9$ training levy-reimbursement schemes ("training funds") ${ }^{40}$ and wage subsidies. There is considerable debate about the effectiveness of such programs. With some exceptions, assistance for enterprise training has generally not been successful. It has been particularly difficult to reach large numbers of small firms.

53. There are only a few studies on the effects of wage subsidies on the provision of training. Analyses in Australia suggest that the effect may be positive, if weak, although there are indications that subsidization of apprentices has led to displacement of other, unsubsidized workers. ${ }^{41}$ Literature on the effects of tax exemptions is also scant. In Chile and Brazil, where some evaluations have been carried out, the main beneficiaries are large enterprises in a few dynamic sectors of the economy. ${ }^{42}$ Evidence on the direct subsidization of training expenses indicates a positive impact on the amount of training provided by enterprises, but the effect on quality is uncertain. Some evidence from Latin America indicates that small firms gain little benefit from reimbursements. ${ }^{43}$

54. A recent survey of 100 studies of active labor market programs found outcomes varying by type of intervention and type of training. There was limited impact in training programs aimed at long-term unemployed, retraining for laid-off workers, training of youth, and wage subsidy programs. Impact of subsidies for training was uncertain. Tax exemptions had some impact but the benefits accrued mostly to larger firms; SMEs have in general not benefited. Over $75 \%$ of the programs had limited success. ${ }^{44}$

55. Among the success stories is Singapore. Here, a levy on the wages of unskilled workers goes into a Skills Development Fund which is used to upgrade the workforce through training grants to enterprises. Training reached $21 \%$ of the labor force in 1985 . By most measures these training grants have been successful. ${ }^{45}$ More recently, matching

\footnotetext{
${ }^{37}$ World Bank (2002), chapter 2.

${ }^{38}$ Most common in Latin America (e.g. Brazil, SENAI; Colombia, SENA; Peru, SENATI and Guatemala, INTECAP). Seem as too supply driven and unresponsive to new skill needs.

${ }^{39}$ Brazil, Malaysia, Pakistan and Chile have used tax incentives with mixed experiences - typically subsidize firms which already train.

${ }^{40}$ Allows companies to eliminate or reduce payroll levy by amount of training provided — used in France, Australia and Korea. Scheme provides flexibility in use of funds; but creates monitoring and abuse problems or degenerates into revenue-raising policy.

${ }^{41}$ Middleton, Ziderman and van Adams (1993).

${ }^{42}$ Middleton et. al., op. cit.

${ }^{43}$ Middleton et. al., op. cit.

${ }^{44}$ Dar and Tzannatos (1999).

${ }^{45}$ Middleton et. al., op. cit.
} 
grant schemes have been used to assist in building a "training culture" by providing both an incentive and a means of investing in training as in Mexico's CIMO program. ${ }^{46}$

Relatively successful training programs for the informal sector have been located in Peru, Botswana, Zambia, Costa Rica and Argentina, run mainly by NGOs. ${ }^{47}$ When combined with donor assistance programs they have proved effective. In general, as a study of training programs in seven developing countries show, private-sector provided training has had significant impact on productivity while the effectiveness of government sponsored training programs has been relatively poor. ${ }^{48}$

\section{World Bank projects}

56. In recent years, project related training, including investments in sectoral training institutions has varied between $\$ 300-\$ 500$ million a year, and has accounted for 3 percent of WB lending. Several World Bank reviews in the 1980s identified the problems that plague training projects - weak national capacity for managing and delivering training, lack of incentives to organizations and employees to undertake training, and lack of coordination among national training organizations. Project-related training investments that relied heavily on external consultants to design and deliver training failed to overcome these limitations, and the results of these investments were mixed, at best. ${ }^{49}$

\section{Support to technology development}

57. Almost all countries have schemes for stimulating and supporting private R\&D, helping technology development in SMEs, and allowing firms to pool their resources in pre-competitive technological effort. At the institutional level, most countries provide technological 'public goods' such as standards, measurement, information, productivity raising services for SMEs, and basic research. Lately, there has been renewed interest in techno-parks, clusters and incubators as a means of jumpstarting economic growth in regions whose economies are disproportionately concentrated in slow growth industries. Technology incubators in particular aim to help tenant firms gain access to, apply, and market technical knowledge in their infancy stages.

58.Evidence from developed countries show some positive results. For example, in the U.S., $80 \%$ of incubator "graduates" survive after five years compared to a survival rate of only around $40 \%$ after five years for the general population of firms. Australian data shows that $50 \%$ of graduate firms were still in business compared to only $5 \%$ of nonincubator firm. In France, only 8-20\% of incubator firms depending on the technology group failed compared to $31 \%$ of new firms in general. ${ }^{50}$ On the other hand, some studies

\footnotetext{
${ }^{46}$ Minowa (2000),

${ }^{47}$ NGOs are also involved in apprenticeship type programs, as in the Philippines where the NGO organization Dualtech has targeted apprenticeship programs for poorer students. Other examples of relative success include the Kenya voucher program, Cote D'Ivoire's training program for the informal sector and the Grassroots Management Training Program for women in India (Middleton, et. al op. cit.).

${ }^{48}$ Tan and Batra (1995), Batra (1999, 2000).

${ }^{49}$ Middleton et. al., op. cit.

${ }^{50}$ OECD (1997). It is not clear if there is any self-selection bias here. Self-selection bias may occur if firms are admitted to the incubators only after intensive screening, which weeds out weaker firms, or if only the more dynamic firms seek entry into incubators.
} 
report that nearly 50 percent of techno-parks never reach viability and nearly half of those that do are forced to diversify from research- based activities into other types of functions. ${ }^{51}$ The record of public technology institutions in enhancing industrial productivity is generally not impressive. In many cases, research institutions have tended to be science (pure research) rather than demand-driven In some, governments have made them 'mission oriented', pushing advanced technologies that have little relevance to industry or little chance of commercial application. SME extension services have not been market-driven, but tended to be passive and bureaucratic. The granting of large research subsidies has sometimes added to the profits of large companies that would have undertaken research in any case. However, public policy intervention has made some difference in this area as in Korea, Taiwan (China). In an appropriate incentive framework, technology institutions can make a significant contribution to technology upgrading. ${ }^{52}$ In some countries, with government funding drying up, such institutions have become more market-oriented and even earning income from the sale of their services to firms. ${ }^{53}$

\section{World Bank projects}

59. A 1995 OED evaluation of the World Bank's lending for industrial technology in six countries found mixed results. ${ }^{54}$ In three countries, the World Bank projects had limited impact. In Hungary, impact was limited because of distortions in the industrial and incentive environment. In Mexico, while the project facilitated the formulation of a new technology policy by financing a study, it failed to achieve its main objective, i.e., promote $\mathrm{R} \& \mathrm{D}$ in the private sector and privatization of research institutes. In Indonesia, while the project helped enlarge the skill base by sending graduates abroad for higher training, it did not enhance the technological capabilities of Indonesian industry. Indeed the impact was perverse because the project focused on some protected, inefficient, socalled "strategic" industries and thereby helped divert scarce skill and training resources from institutions that were geared to serving the technological needs of the private sector.

60. Projects in India, Korea and Spain were relatively successful. In India, the project assisted the private-sector industrial enterprises in acquiring technology from abroad, the innovators to have access to venture-capital funds, and a number of research and development institutes to direct their efforts towards the needs of industry. In Korea, three technology loans that financed KTDC (Korea Technology Development Corporation) contributed to promoting R\&D activities in SMEs. Finally, in Spain, the project was, to some extent, instrumental in encouraging and promoting efforts by CDTI (Centro para el Desarrollo Technologico Industrial) to develop new processes and products, and to bring them to the point of commercialization.

\footnotetext{
${ }^{51}$ Luthria (2000).

${ }^{52}$ Iqbal and Urata (2001).

${ }^{53}$ In India, following the restructuring of the Center for Scientific and Industrial Research (CSIR) network of institutions, contractual research incomes went up from negligible to as high as 70 percent of total revenues in some cases. These institutions have not only been able to assist firms through joint problem solving, but by virtue of having weaned themselves from government support have been able to survive the massive budget cuts that are symptomatic of research funding world-wide.

${ }^{54}$ Najmabadi and Lall (1995). The study covered India, Indonesia, Hungary, Korea, Mexico and Spain.
} 
61. Four other, recently completed, World Bank projects also show mixed results. A matching grant scheme in Mauritius intended to help fund technology transfer projects in 154 private firms. An econometric study of its impact found that while there was substantial increase in sales and exports in these firms, the increase was not significantly different from that in firms which had not received the same support. ${ }^{55}$ An agricultural technology project in Mexico, which sought to improve agricultural productivity through generation and diffusion of new technology, had a poor disbursement record because government shifted attention away from agricultural research and extension. ${ }^{56}$ However, a science and technology infrastructure project in Mexico was successful. Among other things, it helped create the Mexican National Center for Metrology which appears to be have been helpful in promoting the competitiveness of the Mexican industry and in attracting foreign investment. ${ }^{57}$ Finally, a project aimed at supporting private sector R\&D in Turkey found good results, on balance. This $\$ 100 \mathrm{~m}$ loan to Turkey for a Technology Development Project contained a $\$ 43.3 \mathrm{~m}$ component to support the establishment of a Technology Development Foundation. Its aim was to stimulate private investment in industrial technology development by providing seed capital for projects through matching finance for market-driven private sector R\&D. By the end of 1998, it had funded 84 projects of which 46 had been completed. 64 percent of the funded projects were SMEs. Of the 46 completed projects, 74 percent were technically and commercially successful, 20 percent were technically successful but commercially unsuccessful, and 6 percent were technically unsuccessful. The commercially unsuccessful projects may also have added to the technical knowledge base of the company, and induced firms to persist in R\&D efforts. The successful projects were able to increase exports of the firm between 5 and 45 percent depending upon the year of completion. ${ }^{58}$

\section{Conclusions}

62. Programs involving direct support to private firms in developing countries, such as those analyzed above, are in many ways similar to the activities of venture capitalists. Many of the ventures supported through such programs are high-risk with a relatively low probability of success. A smaller number have high returns, both private and social, often with significant spill-over in the economy. Thus, it is not surprising that the record of public support to private firms in developing countries has been mixed with many projects demonstrating poor returns. The challenge is to design programs in a manner such that there is an adequate number of successful ventures, relative to the unsuccessful ones, to justify the resources expended on these programs. The experience summarized in this note suggests that this would require the imposition of certain disciplines on the programs.

63. First, programs should not be carried out in an unsound investment climate. They may supplement on-going efforts at improving the climate but the minimum pre-

\footnotetext{
55 Biggs (1999).

${ }^{56}$ World Bank (1997).

${ }^{57}$ World Bank (1998).

${ }^{58}$ Source: Implementation Completion Report for Technology Development Project, Turkey, 1998.
} 
requisites of a sound investment climate should be in place. This includes macroeconomic stability, freedom of entry and exit, reasonably well-functioning markets, adequate physical infrastructure, sound property rights, and effective legal and judicial systems.

64. Within such an environment, credit programs may produce good results if credit is provided at market rates. Experience shows that subsidized financing has not promoted productive investment and operations. Loans to final borrowers must be priced to cover costs to ensure efficient use of resources. This, in addition to lowering transactions costs and risks, is important for the programs to be cost-effective and sustainable.

Establishing market based interest rates for SME lending and micro finance has been a significant achievement in credit programs in countries where these programs have worked. The broader lessons about the design of financial products for private parties also apply to micro-finance institutions and SME programs. The basic rules of markets apply as elsewhere.

65. The evidence also suggests that business development services need to be market driven. The design of programs to provide such services needs to examine existing markets for such services carefully, identifying sources of market failure and developing appropriate interventions accordingly. Facilitating the flow of market information could be one such intervention, given that lack of information is often a cause for market failure. The government's role should be restricted to establishing a suitable environment for market transactions and avoiding the crowding out of private providers through direct provision of competing services. It is also important to systematically monitor performance in order to ensure cost control, appropriate outreach, and client satisfaction.

66. Certain activities may qualify for subsidies if there are strong externalities associated with them. These could include research and training, and strengthening of institutions with public goods characteristics. Here, it is important that the subsidies are transparent and linked to results, perhaps through output-based financing disciplines. Cost-effective evaluation methods should be built into subsidy-dependent programs so that it is possible to determine the subsidy-equivalence or subsidy-dependence of such schemes. 


\section{BIBLIOGRAPHY}

Batra, Geeta. 1999. "Skills Upgrading and Competitiveness in Guatemala," mimeo, Washington D.C.: World Bank.

Batra, Geeta. 2000. "Enterprise Training and Productivity in Nicaragua," mimeo, Washington D.C.: World Bank.

Biggs, Tyler. 1999. "A Microeconometric Evaluation of the Mauritius Technology Diffusion Scheme”, RPED Discussion Paper 108. Washington D.C.: World Bank.

Dar, Amit and Zafiris Tzannatos. 1999, "Active Labor Market Programs: A Review of the Evidence from Evaluations." Washington D.C.: World Bank.

Demirguc-Kunt, Asli and Vojislav Maksimovic. 1996. "Financial Constraints, Uses of Funds, and Firm Growth: An International Comparison." World Bank Policy Research Working Paper No. 1671. Washington, D.C.: World Bank.

Evenson, R. 1997. "The Economic Contributions of Agricultural Extension to Agricultural and Rural Development," in Improving Agricultural Extension: A Reference Manual, Food and Agricultural Organization of the United Nations, Rome 1997.

Greenwald, Bruce and Joseph Stiglitz. 1986. "Externalities in Economies with Imperfect Information and Incomplete Markets," Quarterly Journal of Economics, 101: 229-64.

IFC. 2000. An Evaluation of IFC's Investments through the Africa Enterprise Fund, Report to CODE, Washington D.C.: International Finance Corporation.

ILO. 2001. "Business Development Services for Small Enterprises: Guiding Principles for Donor Intervention." (Prepared by the Committee of Donor Agencies for Small Enterprise Development at the World Bank, Washington D.C.) Geneva: International Labor Organization.

Iqbal, Farrukh, and Shujiro Urata (eds.). 2001. Small Firm Dynamism in East Asia. WBI Working Papers. Washington D.C.: World Bank.

Keesing, Donald and Andrew Singer. 1990. "Development Assistance Gone Wrong: Why Support Services Have Failed to Expand Exports." WPS 543. Washington D.C.: World Bank.

Luthria, M., 2000. "Strengthening Technological Capability in Industrializing Countries." Washington D.C.: World Bank. 
Middleton, John, Adrian Ziderman and Arvil Van Adams (eds). 1993. Skills for Productivity-Vocational Education and Training in Developing Countries, Washington, D.C.: World Bank.

Minowa, Mari. 2000. "Impact Evaluation of Three Training Programs in Mexico", in I. Gill, Fred Fluitman and Amit Dar (eds.), Vocational Education and Training Reform, World Bank-ILO.

Morduch, Jonathan. 1999. "The Micro-finance Promise," Journal of Economic Literature. 37. pp 1569-1614.

Najmabadi, F. and Sanjaya Lall. 1995, "Developing Industrial Technology: Lessons for Policy and Practice," OED Evaluation Study, Washington D.C.: World Bank.

Nugent, Jeffrey and Seung-Jae Yhee. (forthcoming). "Small and Medium Enterprises in Korea: Achievements, Constraints and Policy Issues". WBI Working Paper. Washington D.C.: World Bank.

OECD. 1997. "Small Businesses, Job Creation and Growth: Facts, Obstacles and Best Practices.”, Paris: OECD.

OED. 1993. A Review of Bank Lending for Agricultural Credit and Rural Finance (1948-1992). Washington D.C.: World Bank.

OED. 1996. A Review of Bank Lending for Agricultural Credit and Rural Finance (1948-1992): A Follow-Up. Washington D.C.: World Bank.OED. 1999. The World Bank and Micro-enterprise Finance: From Concept to Practice, Impact Evaluation Report, 1999. Washington D.C.: World Bank.

Purcell, Dennis L. and Jock R. Anderson. 1997. "Agricultural Extension and Research: Achievements and Problems in National Systems." OED Evaluation Study. Washington D.C.: World Bank.

Robinson, Marguerite S. 2001. The Micro-finance Revolution-Sustainable Finance for the Poor. Washington D.C.: World Bank.

Tan, Hong and Geeta Batra. 1995. Enterprise Training in Developing Countries: A Cross-National Study. Washington D.C.: World Bank.

Umali-Deininger, R. 1997. "Public vs. Private Agricultural Extension: Partners or Rivals." World Bank Research Observer, 12 (2).

Webster, Leila M., Randall Riopelle and Anne-Marie Chidzero. 1996. "World Bank Lending for Small Enterprises 1989-1993.” World Bank Technical Paper No. 311, Washington D.C.: World Bank. 
Webster, Leila. 1991, "World Bank Lending for Small and Medium Enterprises: Fifteen Years of Experience." World Bank Discussion Paper No. 113. Washington D.C.: World Bank.

William Steel, Jim Tanburn and Kris Hallberg, "The emerging strategy for building Business Development Service Markets", in Jacob Levitsky eds. "Business Development Services: A Review of International Experience”, 2000.

World Bank. 1997. "Mexico: Agricultural Technology Project." Implementation Completion Report No. 17025. Washington D.C.: World Bank

World Bank. 1998. "Mexico: Science and Technology Infrastructure Project." Implementation Completion Report No. 18763. Washington D.C.: World Bank.

World Bank. 2001. World Development Report 2002 - Building Institutions for Markets. Washington D.C.: World Bank.

Yaron, J. and Stephanie Charitonenko. 2000, "Update of Vision to Action: Rural Finance Section." Washington D.C.: World Bank.

Yaron, Jacob. 1997. "Successful Rural Finance Institutions." World Bank Discussion Paper No. 150. Washington D.C.: World Bank.

Zaman, Hassan. 1999. "Assessing the Impact of Micro-credit on Poverty and Vulnerability in Bangladesh.” World Bank Policy Research Working Paper No. 2145. Washington D.C.: World Bank. 


\section{Annex 1: List of World Bank projects with credit line components ${ }^{1}$}

Africa: Third Regional Development. Approved: FY90 Closed: FY98

Bangladesh: Export Development. Approved: FY89; Closed: FY94

Bangladesh: Private Sector Industrial Credit. Approved: FY92; Closed: FY98

Bolivia: Private Enterprise Development. Approved: FY90; Closed: FY98

Bulgaria: Private Investment and Export Finance. Approved: FY93; Closed: FY98

China: Rural Industry Technology. Approved: FY91; Closed: FY98

Ecuador: Private Sector Development. Approved: FY93; Closed: FY99

Estonia: Financial Institutions Development. Approved: FY95; Closed: FY98

Ghana: Private Enterprise and Export Development. Approved: FY93; Closed: FY98

Hungary: Agro-processing Modernization. Approved: FY88; Closed: FY98

Hungary: Energy Development and Conservation. Approved: FY89; Closed: FY98

Hungary: Product Market Development. Approved: FY93; Closed: FY99

Hungary: Third Industrial Restructuring. Approved: FY89; Closed: FY97

Indonesia: Financial Sector Development. Approved: FY93; Closed: FY98

Indonesia: Industrial Restructuring. Approved: FY89; Closed: FY96

Lesotho: Industrial and Agro-Industries. Approved: FY91; Closed: FY98

Macedonia: Private Sector Development. Approved: FY96; Closed: FY00

Malawi: Financial Sector and Enterprise Development. Approved: FY91; Closed: FY98

Morocco: Financial Sector Development. Approved: FY91; Closed: FY99

Morocco: Industrial Finance. Approved: FY90; Closed: FY96

Mozambique: Small and Medium Enterprise. Approved: FY 90; Closed: FY98.

Poland: Agro-industries Export Development. Approved: FY90; Closed: FY98

Poland: Industrial Export Development. Approved: FY90; Closed: FY00

Poland: Private Enterprise Development. Approved: FY92; Closed: FY99

Senegal: Industrial Reconstruction. Approved: FY88; Closed: FY98

Sri Lanka: Private Financial Development. Approved: FY93; Closed: FY99

Tonga: Second Tonga Development Bank. Approved: FY90; Closed: FY96

Trinidad and Tobago: Business Expansion and Industrial Restructuring. Approved: FY92;

Closed: FY99

Turkey: Private Investment Credit. Approved: FY91; Closed: FY97

Turkey: Agro-Industry. Approved: FY89; Closed: FY97

1. This is not a comprehensive list of World Bank projects with credit line components. This is the sample of projects for which Operations Evaluation Department evaluations or implementation completion reports are available and which form the basis of the discussion on World Bank credit line projects in Section IIA. 